\title{
PESQUISA DE SATISFAÇÃO DO PLANTÃO PSICOLÓGICO NA CLÍNICA ESCOLA DA UFC: PENSANDO ATENDIMENTO, QUALIDADE E ACOLHIMENTO
}

DANTAS, J.B. ${ }^{1}$ R. N. SILVA²; M. O. Ferreira ${ }^{3}$; M. A. Procópio ${ }^{4}$; F. I. Lima Filho ${ }^{5}$

${ }^{1}$ Professora Adjunta e Chefe do Departamento de Psicologia da Universidade Federal do Ceará (UFC). ${ }^{2}$ Bolsista e graduanda pela Universidade Federal do Ceará (UFC). E-mail: robertanunesilva@gmail.com; ${ }^{3}$ Bolsista e graduanda pela Universidade Federal do Ceará (UFC). E-mail: oliveiramayara92@ @otmail.com; ${ }^{4}$ Psicóloga na área da Educação em Sobral/CE. E-mail: assuncaoprocopio@ gmail.com; ${ }^{5}$ Bolsista e graduando pela Universidade Federal do Ceará (UFC). E-mail: ilofilholima@ gmail.com .

Artigo submetido em 02/09/2018

\section{RESUMO}

O presente artigo tem por objetivo realizar uma apresentação geral da pesquisa de satisfação sobre o serviço prestado pelo projeto de extensão plantão psicológico. Pesquisa essa que foi aplicada durante os últimos três anos. De uma forma geral, investigou-se, por meio de instrumento específico e personalizado, se os objetivos almejados pelo serviço no que tange a qualidade e a promoção de saúde mental estavam sendo alcançados. Buscou-se saber se o plantão psicológico realizado na Clínica Escola da Universidade Federal do Ceará, realmente fomentava um espaço de escuta, acolhimento, esclarecimento e promoção à saúde mental. Os resultados indicam, de forma prevalente, que o
\end{abstract}

plantão consegue atingir seus objetivos. Vale ressaltar que, não é apenas a comunidade em geral que é beneficiada pelo projeto, mas os alunos no âmbito de oportunizar espaços diferentes para realização das práticas psicológicas. Tendo acesso a uma formação que prioriza o trabalho multiprofissional, a escuta qualificada e a promoção de saúde mental. Conclui-se que o Plantão Psicológico vem se tornando um serviço de referência no Estado do Ceará por qualificar o serviço e trabalhar a demanda da comunidade e ofertar uma formação mais crítica e vocacionada aos novos contextos contemporâneos.

PALAVRAS-CHAVE: Plantão psicológico. Pesquisa de satisfação. Acolhimento. Saúde mental.

\section{PSYCHOLOGICAL EMERGENCY SATISFACTION SURVEY AT UFC SCHOOL CLINIC: THINKING ATTENDANCE, QUALITY AND RECEPTION}

\begin{abstract}
This article aims to present a general presentation of the satisfaction survey about the service provided by the psychological extension project. Research that has been applied during the last three years. In general, it was investigated, through a specific and personalized instrument, if the objectives sought by the service regarding the quality and promotion of mental health were being achieved. We sought to know if the psychological work done at the School Clinic of the Federal University of Ceará, really fostered a space for listening, receiving, clarifying and promoting mental health. The results indicate, on a prevailing basis, that the shift can achieve its
\end{abstract}

objectives. It is noteworthy that, it is not only the general community that is benefited by the project, but the students in the scope of providing different spaces for achievement of psychological practices. Having access to training that prioritizes multiprofessional work, qualified listening and the promotion of mental health. It is concluded that the Psychological Plan has become a reference service in the State of Ceará for qualifying the service and working the demand of the community and offer a more critical training and vocation to the new contemporary contexts.

KEYWORDS: Program Agenda. Health Strategy. Hiperdia. Intervention.

\section{INTRODUÇÃO}


O plantão psicológico enquanto projeto de extensão, vinculado a Pró-Reitoria de Extensão da Universidade Federal do Ceará (PREX-UFC), surge no ano de 2015 tendo como maior objetivo oferecer à comunidade em geral um espaço de acolhimento em momentos de crise. Atualmente, o plantão psicológico da UFC ocorre em três espaços, na Clínica Escola de Psicologia da UFC, no posto de saúde (UBS) Anastácio Magalhães e no Hospital e Maternidade Gastroclínica, tendo em suas equipes estagiários e extensionistas. Por ser compreendido como uma modalidade de atendimento que transborda o espaço tradicional do consultório privado, bem como as cristalizações das práxis psicológicas, o Plantão Psicológico em sua postura de ousadia e transformação pode se inserir em diversos contextos sociais, como escolas, CREAS, CAPS, hospitais e instituições de defesa de direitos (TASSINARI; DURANGE, 2012). Para este artigo destacaremos, no entanto, o plantão na Clínica Escola de forma mais direta e expositiva. Tendo como base de execução e proposta, o atendimento ofertado em momentos de crise e urgência e, sobretudo, se configurando como um espaço sempre disponível à população em geral, a Clínica Escola da UFC vem se tornando uma referência de atendimento e formação. Todo este contexto requer que a equipe se encontra em constante capacitação no sentido de ofertar uma escuta de qualidade. Toda terça-feira, o plantão psicológico conta com uma equipe que é estimulada a ir além do simples diagnosticar. Não são os fatos, os diagnósticos ou possíveis enquadramentos patológicos que direciona a atenção de quem está a ofertar o serviço, mas o sujeito em sua integridade, totalidade e singularidade. Sujeito reconhecido em sua diferença e legitimado em seu discurso portador de um sentido que traduz sua biografia de vida e seu momento presente. Assim, o plantão psicológico volta-se para aquele que sofre, procurando ofertar uma prática de cuidado que valora a busca por autonomia emocional e possibilidades de enfretamento da situação de crise vivida, de modo próprio, por cada usuário que comparece ao nosso serviço.

À vista disso, podemos adentrar nas características mais administrativas do serviço. O sujeito que busca atendimento psicológico no plantão não entra em uma fila de espera que pode levar meses. Ele é atendido no mesmo dia em que busca o serviço. Basta repassar o nome ao extensionista, membro da equipe da sala de espera, responsável pela inscrição e aguardar ser chamado para o atendimento. Após o atendimento é realizada a supervisão, em caráter coletivo e colaborativo, de modo a pensar as questões advindas do atendimento e as possibilidades de cuidado que se traduzem nos diferentes caminhos oportunizados pelo serviço: o atendimento pode ser configurar como único, como espaço e possibilidade de retorno para eventuais necessidades ou por interesse do próprio usuário, como possibilidade de realização de um plano 
de atendimento de curta duração considerando a demanda trazida bem como, em última instância, em função de quadros de sofrimento de sofrimento psíquico mais grave, pode ser realizado o encaminhamento para demais equipamentos de saúde da nossa rede de apoio. Em resumo, é possível afirmar que, no que diz respeito ao atendimento, há um primeiro acolhimento, o caso é analisado em supervisão e o direcionamento mais adequado é decidido em uma discussão coletiva e, por vezes, multiprofissional.

Em relação à supervisão, a avaliação ocorre a partir de uma ação que encontra suporte no referencial fenomenológico-existencial. Guiando-se principalmente pela fenomenologia hermenêutica. Constrói-se, dessa forma, uma visão de sujeito lançado em mundo de possibilidades e em constante devir. É, justamente, por compreender o ser enquanto possibilidade e abertura que faz sentido ofertar um espaço de escuta e acolhimento. Um espaço que abre mão dos fatos que já foram dados tantas vezes, e que busca fomentar no sujeito a indagação do sentido das coisas. Que convoca o mesmo a se posicionar diante de sua vida e do rumo que vem tomando. (HEIDEGGER, 1989).

É por reconhecer que na contemporaneidade, contexto muitas vezes promovedor de diversas enunciações de sofrimento psíquico e recorrentes diagnósticos estigmatizantes que, acredita-se fazer sentido ter um espaço para momentos de crise e suporte emocional situacional e circunstanciado. O plantão, essencialmente, busca oferecer um serviço de qualidade, de escuta, de acolhimento e de promoção à saúde mental. Este objetivo encontra suporte e ferramentas de análise na aplicação da pesquisa de satisfação junto ao usuário, onde busca-se, fundamentalmente, avaliar os pontos frágeis e fortes do serviço bem como o alcance dos objetivos gerais do projeto de extensão na ampliação de possibilidades de escuta e cuidado.

\section{REFERENCIAL TEÓRICO}

A psicologia clínica, atualmente, é convocado a se reinventar e se repensar como espaço ético, que busca uma nova atitude, um outro olhar sobre o homem e suas relações. Não se configura mais como simples campo de atuação recortada por normativas, espaço ou clientela específica. Podemos dizer, de modo categórico, que a psicologia tem sido demandada a uma adequação de suas práxis diante das novas enunciações e apresentações de sofrimento psíquico advindos na contemporaneidade. Sobre isso, Mahfoud (2013) destaca que a sociedade vem, atualmente, apresentando menos espaços para que as pessoas elaborem suas experiências, de forma que nos encontramos menos sintonizados com nossas próprias questões. Isso significa que o psicólogo precisa estar cada vez mais comprometido ao contexto no qual o sujeito está 
inserido, atentando-se que este é um ser-no-mundo, e por isso em constante processo de construção, ao mesmo tempo que constitui o seu espaço. Essa nova perspectiva exige da psicologia um posicionamento ético e político, e não mais uma prática baseada em uma técnica. E é diante desse contexto contemporâneo de aceleração e urgências, onde o homem encontrase muitas vezes alienado de si, que o Plantão Psicológico se consolida ao longo dos anos como uma prática clínica da contemporaneidade (REBOUÇAS, 2010).

O Plantão Psicológico surge no ano de 1969, coordenado pela professora Rachel Lea Rosenberg no Serviço de Aconselhamento Psicológico (SAP) da Universidade de São Paulo (USP), fruto do anseio de oferecer às pessoas que procuravam o Instituto de Psicologia da Universidade de São Paulo (IPUSP) um atendimento imediato no momento da procura por ajuda, constituindo-se como uma possibilidade às longas filas de espera. Assim, o serviço tem sua gênese em uma clínica escola, possuindo ao mesmo tempo uma certa autonomia frente à instituição, promovendo uma utilização própria do espaço institucional em que estava inserido, de forma que todos eram atendidos (MAHFOUD, 2013). A implantação acontece em um contexto de fortalecimento da Psicologia Humanista no Brasil, chamada "Terceira Força", que se constitui como um movimento de pensadores que iam contra as correntes psicológicas dominantes - psicanálise e behaviorismo, abrindo espaço para o desenvolvimento de novas pesquisas e para uma nova forma de pensar o modelo clínico (REBOUÇAS, 2010).

O plantão é caracterizado por um serviço de atendimento psicológico contendo um tempo e espaço constante, onde o atendimento é realizado por livre demanda, sem tempo determinado. Segundo Mahfoud (2013), a modalidade possui, por seu caráter emergencial e por entender o momento da procura pela escuta como um instante de riqueza de elaboração da experiência, o desafio de estruturar um serviço que acolha o cliente em sua ação, e não como uma etapa para outro processo. Ou seja, o Plantão se constitui como

[...] um tipo de atendimento psicológico que se completa em si mesmo, realizado em uma ou mais consultas sem duração pré-determinada, objetivando receber qualquer pessoa no momento exato (ou quase exato) de sua necessidade para ajudá-la a compreender melhor sua emergência e, se necessário, encaminhá-la a outros serviços. (TASSINARI, 2009, p. 176, grifo nosso).

Nesse sentido, o plantonista se dispõe ao encontro do outro no momento presente, comprometido com uma escuta sensível para os sentidos elucidados, onde o cliente possa se questionar e construir outras possibilidades a partir da experiência vivida, ressignificando assim o seu sofrimento. Sobre a escuta do profissional, ela é "pautada no cuidar e, sobretudo, pautada em promover um espaço em que o próprio usuário cuide de sua condição existencial" (DANTAS et al, 2016, p. 234). Trata-se, antes de tudo, de promover no outro uma convocação 
a pensar sobre seus modos de ser-no-mundo e suas implicações frente à sua história e suas escolhas.

\section{MATERIAIS E MÉTODOS}

Este artigo está pautado na realização de uma pesquisa qualitativa de caráter descritivo, envolvendo a satisfação do usuário sobre o serviço oferecido à comunidade, tendo como local de análise o projeto de extensão Plantão Psicológico na Clínica-Escola da UFC. O serviço, funciona desde agosto de 2015, atendendo todas as terças-feiras a comunidade em geral nos turnos da manhã $(08: 00$ - 12:00) e da tarde $(13: 00$ - 17:00). O projeto é realizado por extensionistas e estagiários que são supervisionados durante todas as 8 horas de atendimento semanais. Ao longo desses três anos de atendimento podemos dizer que mais de 4.000 pessoas com diferentes necessidades e demandas foram atendidas.

Com uma proposta de clínica ampliada e maior atenção à saúde, o projeto vem se destacando na otimização da fila de espera da instituição e na formação dos discentes. A cada semestre esses são qualificados através de capacitações e grupos de estudos oferecidos por professores e profissionais parceiros do Laboratório de Estudos em Psicoterapia, Fenomenologia e Sociedade (LAPFES), seja sobre a prática clínica do Plantão Psicológico ou especificidades das demandas dos atendimentos (luto, ansiedade, depressão, relações amorosas, atendimentos com crianças, et cetera), ou ainda sobre as normas e funcionamento da instituição, além da discussão das questões éticas na escuta psicológica. Todas essas atividades, complementares às 8 horas de atendimento semanais, têm como intuito imbuir o discente de conhecimentos e posturas necessárias para uma escuta de qualidade frente aos seus casos.

Além dos demais contextos onde são desenvolvidos os atendimentos pelo projeto de extensão - hospitalar (1 bolsista) e atenção primária (1 bolsista) —, o Plantão na clínica-escola conta com 31 extensionistas/estagiários (14 pelo turno da manhã e 17 pelo turno da tarde), sendo destes: 1 bolsista; 2 profissionais formadas, psicólogas colaboradoras do LAPFES; além de mensalmente também somar-se à equipe 1 psiquiatra. Em geral, os atendimentos são feitos em dupla, de forma a facilitar a troca de experiências entre os plantonistas. Vale ressaltar que para favorecer essa troca de experiências e por uma peculiaridade da modalidade de Plantão Psicológico - caracterizado pela urgência em momentos de crise e pela dinâmica — não há plantonistas fixos para usuários ou entre as duplas. Assim, terminadas as atividades por semestre, o discente deve construir, para fins de registro e de pesquisas anuais desenvolvidas pelo LAPFES, uma versão de sentido sobre sua experiência enquanto plantonista, seja como conclusão de estágio, seja como extensão. 
Os instrumentos usados no serviço para o atendimento à população são: Ficha de Formulário de Atendimento (FFA); Termo de Ciência (TC); Ficha de Evolução de Atendimento (FEA); e Ficha de Registro de Atendimento (FRA). A FFA é utilizada no primeiro atendimento no serviço e serve para que o plantonista relate de forma sintética - mas abrangente - o atendimento realizado, permitindo que, havendo retorno do usuário ao serviço, outro plantonista possa ler e conhecer um pouco do caso e suas particularidades. O TC é o documento que o usuário assina afirmando estar ciente do funcionamento da clínica-escola, do serviço de Plantão Psicológico, da discussão do caso em supervisão e da possibilidade do uso deste caso em pesquisas (resguardando anonimato total). A FEA é utilizada a partir de um segundo encontro e tem por objetivo manter o controle da evolução dos atendimentos; nela o plantonista também faz relatos breves sobre os sucessivos encontros, de forma que, se necessário, outro estagiário/extensionista possa dar continuidade ao processo iniciado. A FRA registra todos os atendimentos em um turno, registrando a ordem, os plantonistas responsáveis e o encaminhamento dado a cada cliente. Por fim, há ainda a pesquisa de satisfação. Feita para constatar a satisfação do usuário em relação ao serviço (infraestrutura, atendimento, compreensão da proposta), ela é entregue ao usuário sempre ao final do atendimento e conta com 10 afirmativas que ele marca de acordo com seu nível de concordância. A escala usada em cada uma das afirmativas possui 5 pontos cada e vai desde "discordo totalmente" até "concordo totalmente". É com base na pesquisa de satisfação, analisada semestralmente, que o serviço é repensado, ampliado e divulgado. A partir do ano de 2016 iniciamos as aplicações da pesquisa de satisfação sobre o serviço voltada ao usuário, em caráter voluntário. Para este estudo, tivemos como base apenas aqueles atendidos no período de março a junho de 2018. Daqueles que foram atendidos neste período, 216 usuários participaram, voluntariamente, da nossa pesquisa de satisfação. Vale ressaltar que, foram retirados de nosso banco de dados instrumentos incompletos, preenchidos de forma incorreta ou sem os dados específicos sobre o serviço respondidos.

Ao longo dos 3 anos de funcionamento o projeto de extensão Plantão Psicológico ampliou suas atividades, firmou novas parcerias e estreitou as já existentes. A rede de serviços de apoio para encaminhamentos (quando necessário) que já contava com CAPS, Hospital universitário Walter Cantídio, Clínicas-Escolas de outras instituições de ensino superior públicas e particulares, agora também conta com psiquiatras parceiros, projetos e serviços especializados na promoção de saúde frente a diagnósticos, serviços de psicologia a preços acessíveis, além de, como já dito anteriormente, estar de modo pioneiro e inédito no município 
de Fortaleza, desde o início do presente ano, atuando na atenção primária dentro de uma Unidade Básica de Saúde (UBS) Anastácio Magalhães e na atenção terciária no Hospital e Maternidade Gastroclínica.

\section{RESULTADOS E DISCUSSÕES}

Desde o início de funcionamento do plantão, em 2015.2, temos procurado traçar o perfil dos usuários do serviço, procurando conhecer seus dados sócio demográficos e sua percepção sobre estrutura e qualidade do serviço. Nas pesquisas dos dados gerias sobre o serviço realizadas entre 2015 e 2017, vimos que a maioria do nosso público é feminino (66\%), com idade entre 21 e 25 anos (17,19\%), residente nas regionais IV e V (21,36\% cada uma), com o ensino médio completo $(26,37 \%)$ e com renda de 1 a 3 salários mínimos. Nesse período também tivemos grande procura de universitários pelo serviço $(23,78 \%)$, muitos deles com questões referentes à dinâmica universitária e toda a angústia que ela pode gerar, e outros que demonstravam dúvidas quanto ao curso escolhido.

Dando continuidade à todas essas pesquisas, vamos apresentar neste momento os dados referentes a pesquisa de satisfação desde o início de suas aplicações, porém trazendo os dados mais específicos de 2018.1. Durante este primeiro semestre de 2018, dentre o público atendido 216 pessoas, em caráter voluntário, participaram de nossa pesquisa. A quantidade maior de usuários participantes da pesquisa foi no mês de março, o que se justifica pelo período de recesso (janeiro e fevereiro), havendo grande procura tão logo o serviço retoma as atividades semestrais. O mês de maio foi o que teve menor colaboração na pesquisa, com 45 usuários respondendo aos instrumentos.

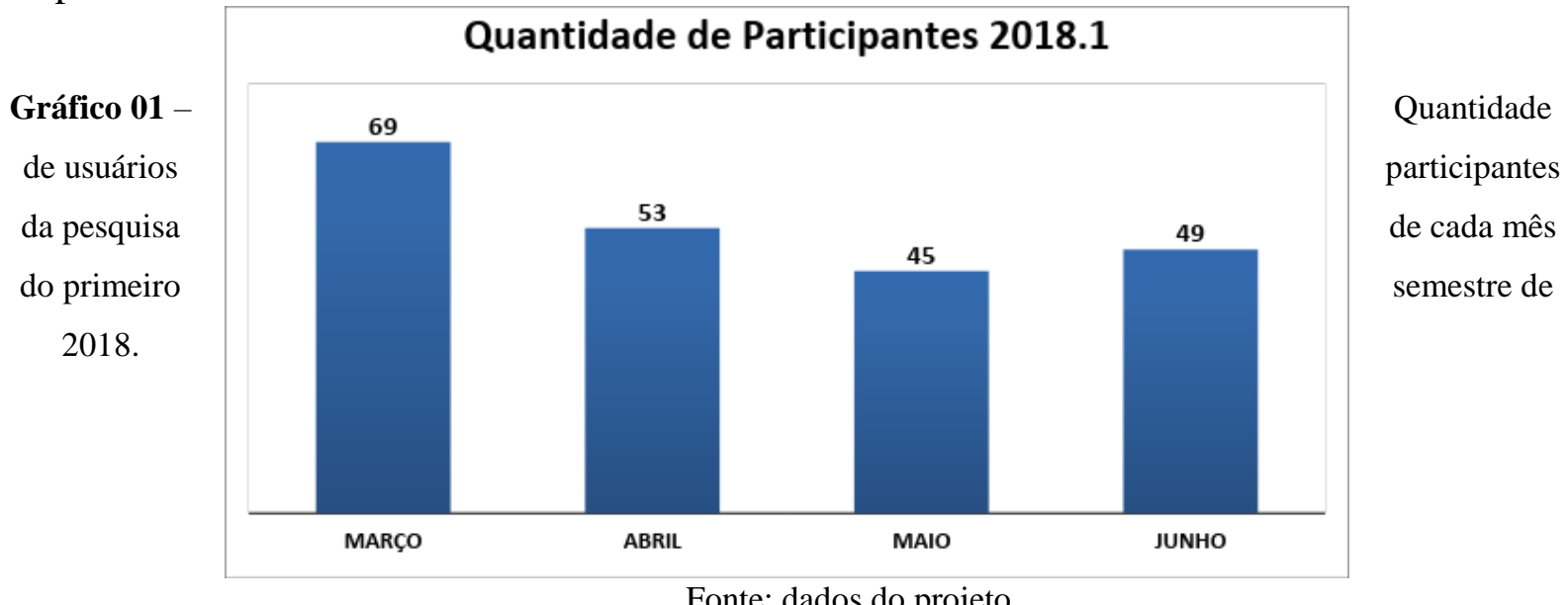

Os gráficos 02, 03, 04 e 05 a seguir, trazem dados sócio demográficos dos usuários do plantão, presentes no instrumento da pesquisa de satisfação, com informações obtidas a partir 
das variáveis gênero, idade, profissão e renda. Podemos inferir que a maioria dos usuários participantes são do gênero feminino (64\%), com idade preponderante entre 21 a 25 anos $(23,10 \%)$. A profissão que sobressai é a de estudante (26,85\%), com renda de 1 a 3 salários mínimos $(74,07 \%)$, mostrando que o público que busca a clínica escola tem um menor poder aquisitivo, e busca um serviço psicológico gratuito e de qualidade. Uma porcentagem considerável de usuários $(23,61 \%)$, não informou sua profissão, o que teria feito diferença no resultado dessa variável.

Gráfico 02 - Gênero dos usuários participantes da pesquisa de satisfação

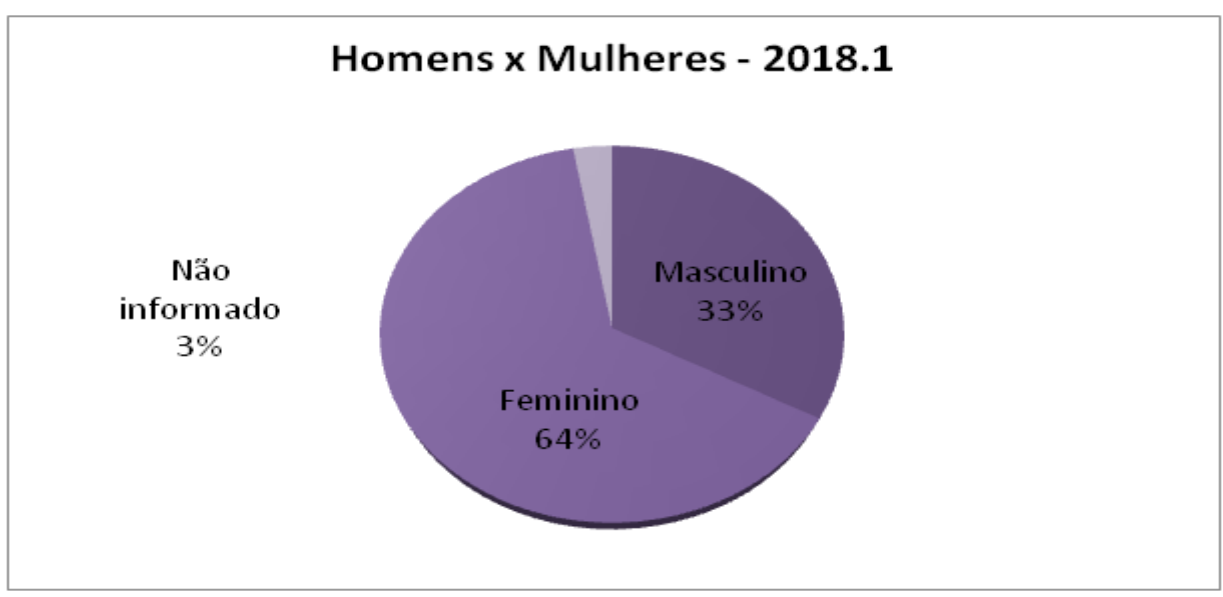

Fonte: dados do projeto

Gráfico 03 - idade dos usuários participantes da pesquisa de satisfação

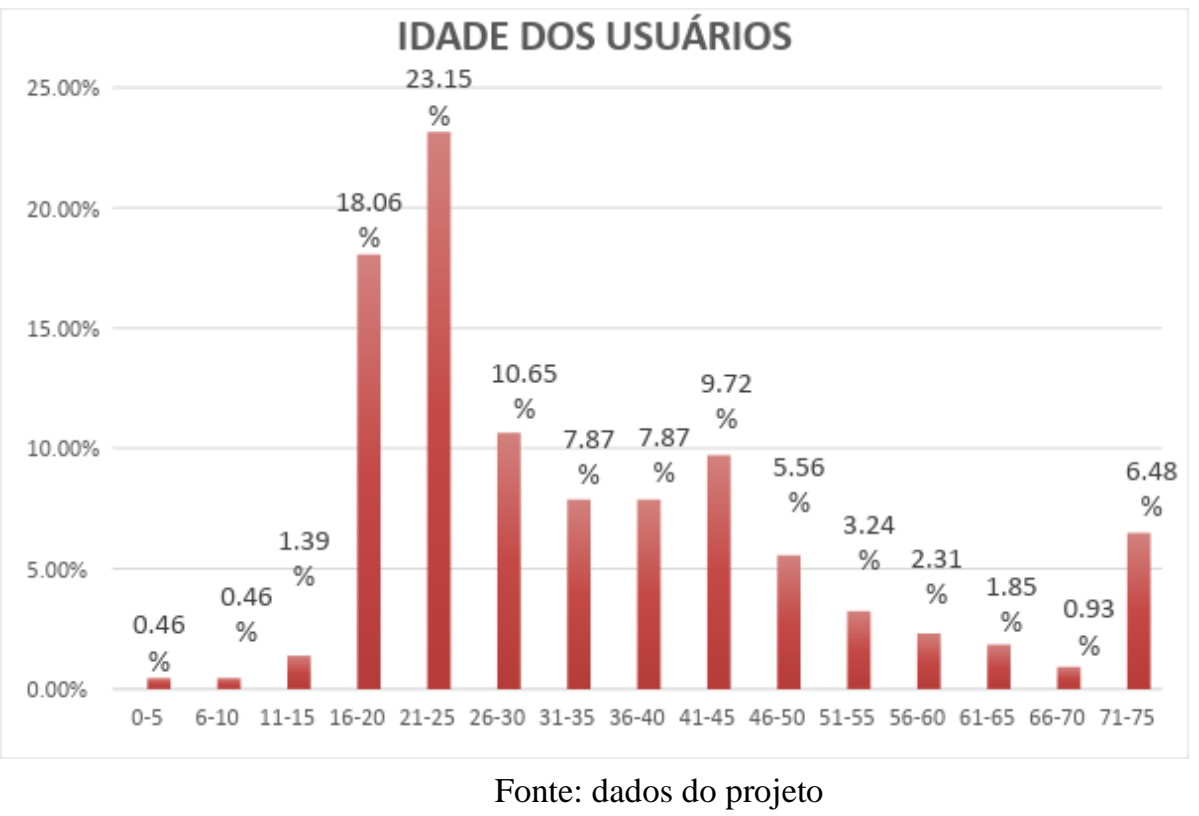


Gráfico 04 - profissão dos usuários participantes da pesquisa de satisfação

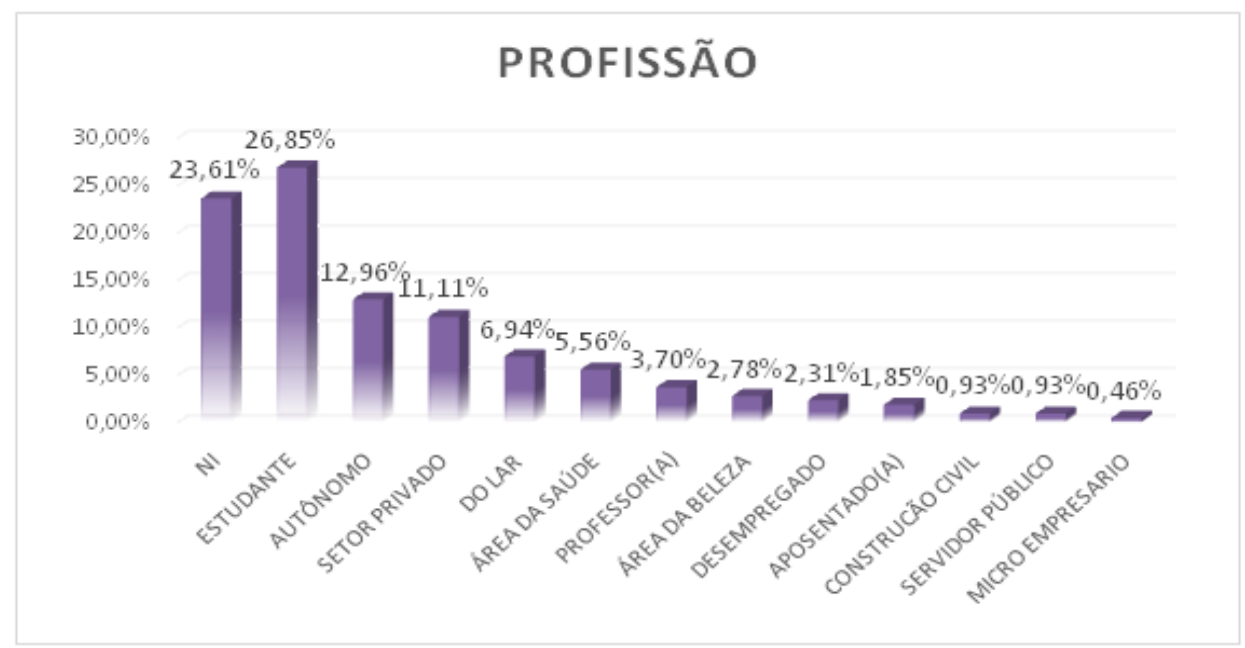

Fonte: dados do projeto

Gráfico 05 - renda dos usuários participantes da pesquisa de satisfação

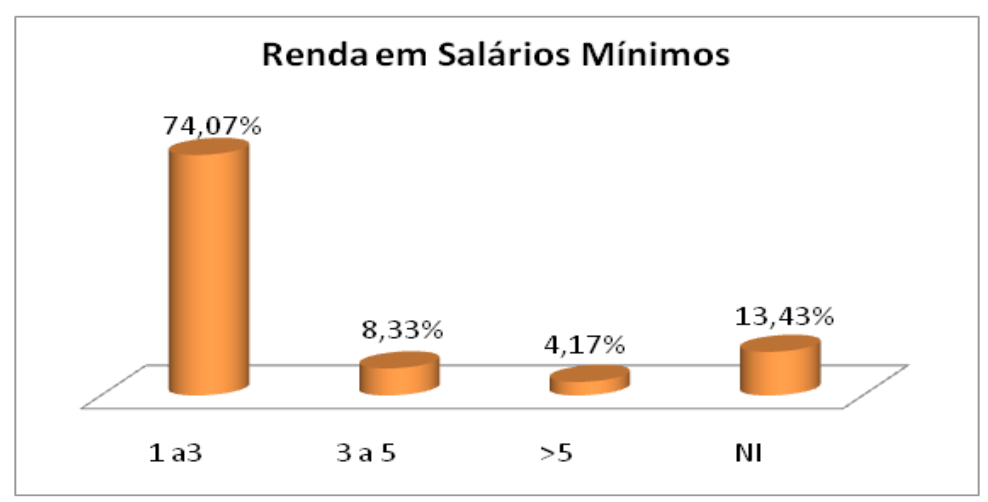

Fonte: dados do projeto

No gráfico 06 e 07 a seguir, podemos ver se o usuário veio ao plantão encaminhado de outro serviço ou procurou espontaneamente e qual foi o motivo da procura ao serviço. O Plantão tem como prerrogativa a demanda espontânea, onde o serviço é procurado numa situação de crise e emergência e os resultados comprovam que o maior número de procura pelos atendimentos se deu por demanda espontânea, as pessoas procuraram o serviço por vontade própria $(69,44 \%)$, poucas foram encaminhadas e $13,43 \%$ não informaram. No motivo das consultas, tivemos um grande número de pessoas que não informaram (25\%) o motivo pelo qual procuraram o serviço, ou por não ter clareza do motivo, ou até por receio, pois sabemos que ainda há preconceito sobre a procura dos serviços psicológicos, embora essa realidade tenha melhorado bastante. O motivo que mais se destacou foi a ansiedade, com 18,06\%, atendimento para os filhos, com $11,57 \%$ e depressão, com $10,65 \%$. 
Gráfico 06 - se o usuário participantes da pesquisa de satisfação veio encaminhado de outros locais

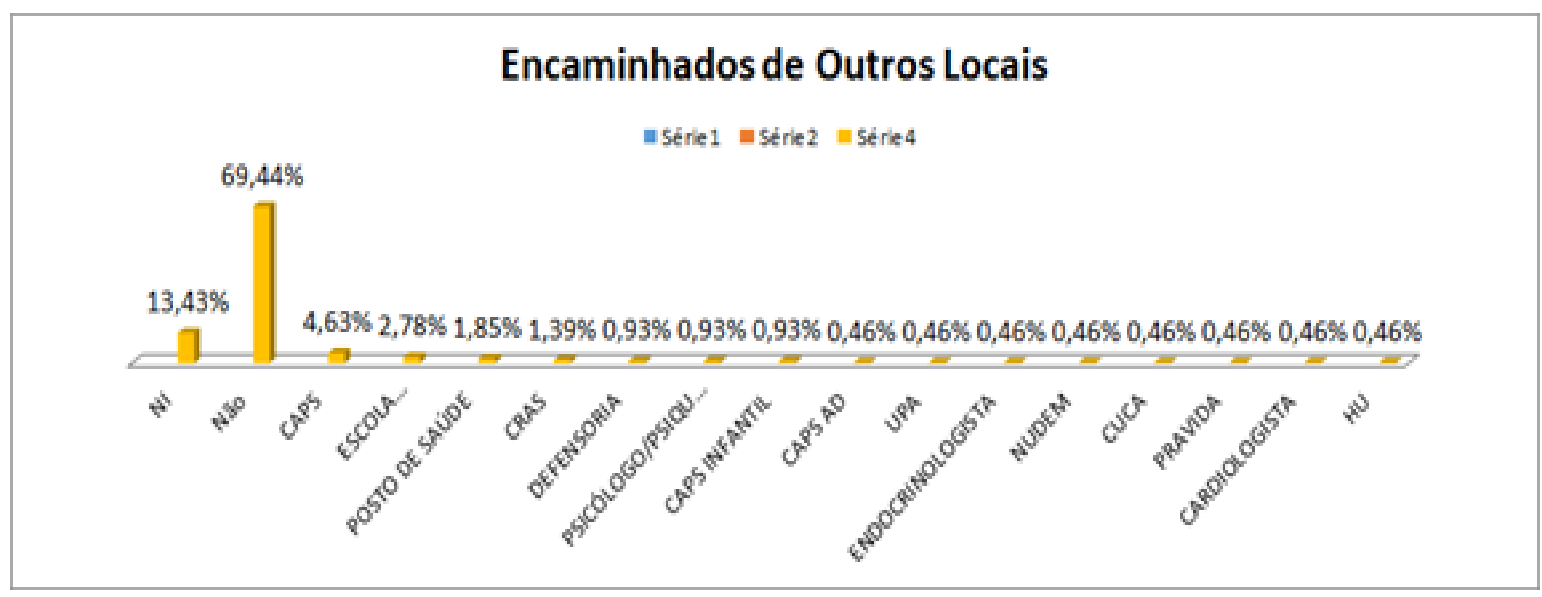

Fonte: dados do projeto

Gráfico 07 - motivo da consulta dos participantes da pesquisa de satisfação

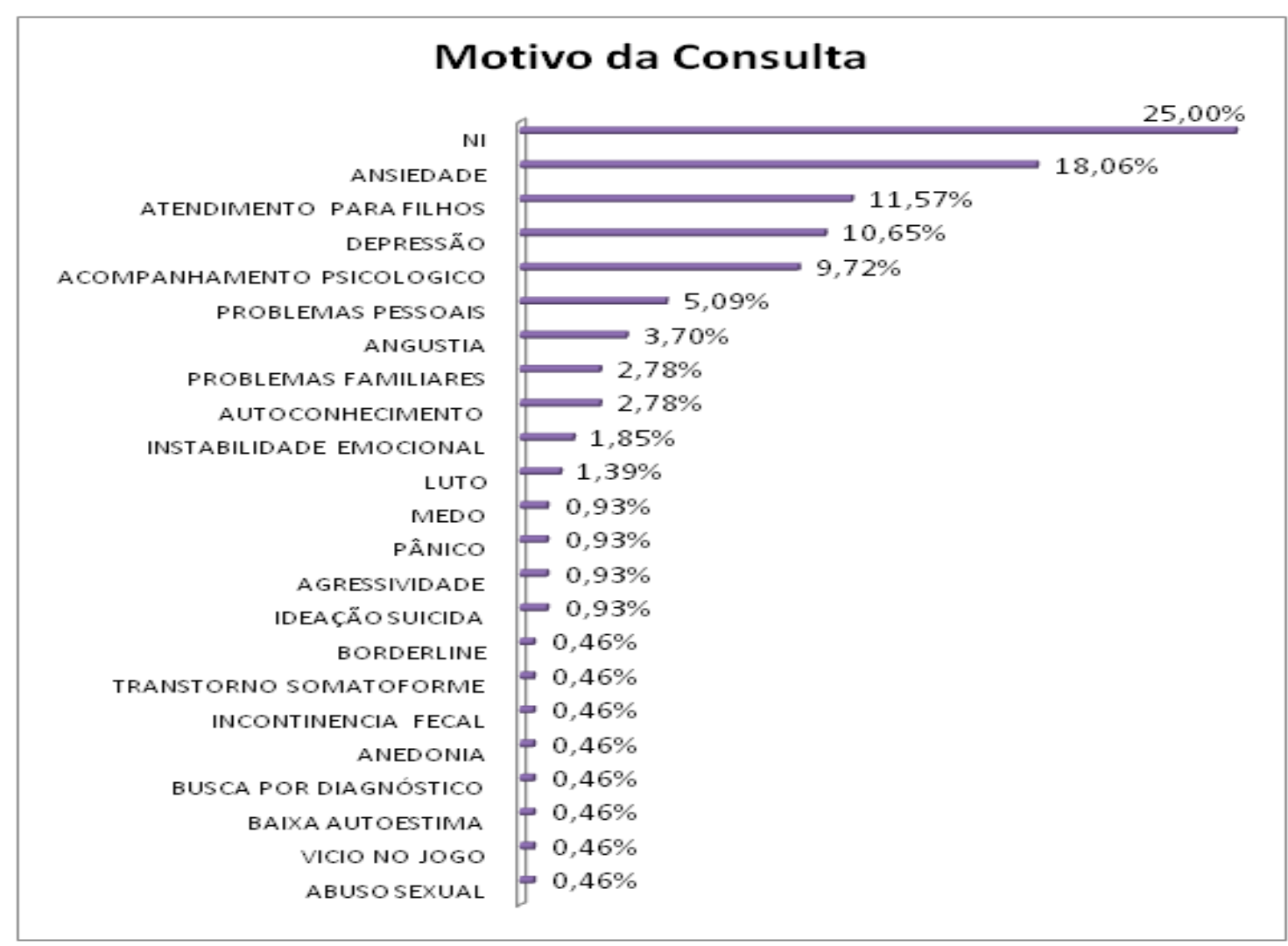

Fonte: dados do projeto

Desde o início do Plantão, em 2015, a equipe sempre procurou conhecer a opinião dos usuários sobre o serviço, no intuito de melhorar, seja no atendimento, na qualidade ou no tempo de espera. Pensando nisso, foi criada esta pesquisa de satisfação, conforme supracitado, mais especificamente em 2016, após um ano de intensos atendimentos a fim de analisar o serviço e perceber pontos de melhoria. Esta pesquisa é composta por 10 afirmativas, onde as respostas 
estão baseadas nos pontos da Escala de Likert para análise dos dados: a) concordo totalmente; b) concordo parcialmente; c) nem concordo, nem discordo; d) discordo parcialmente; e) discordo totalmente. As afirmativas são:

P01: A qualidade da recepção do serviço do Plantão Psicológico foi boa.

P02: O tempo de espera para ser atendido no serviço foi razoável.

P03: O serviço do Plantão Psicológico se mostra bem organizado.

P04: As instalações das salas estão bem preservadas e em funcionamento adequado.

P05: O tempo de atendimento foi suficiente.

P06: Compreendi o funcionamento do serviço do Plantão Psicológico.

P07: O serviço do Plantão Psicológico atendeu minhas necessidades.

P08: Estou satisfeito (a) com o atendimento realizado.

P09: Caso seja necessário, retornarei ao serviço do Plantão.

P10: Com base no meu atendimento, eu recomendaria o Plantão Psicológico para um(a) amigo(a).

No gráfico 08 temos o resultado da pesquisa de satisfação de 2016 a 2017, no gráfico 09 temos o resultado do primeiro semestre de 2018 com os dados mais recentes da pesquisa. No gráfico 08, que corresponde ao período de 2016 a 2017, vemos que a afirmativa 04, referente às instalações da clínica, foi a que obteve a maior porcentagem de satisfação, com mais de $90 \%$ e a afirmativa 02 , sobre o tempo de espera para ser atendido, foi a que teve menor satisfação, em torno de $65 \%$. Podemos inferir o seguinte a respeito dos resultados encontrados: a clínica escola tem uma infraestrutura nova, passou por reformas recentes, as paredes são pintadas pelo menos anualmente, o que a deixa com aparência de nova, limpa. As salas são organizadas, com móveis novos, tem ar-condicionado, proporcionando conforto e bem-estar aos usuários, sendo um dos itens de maior satisfação dos participantes da pesquisa. Com relação ao tempo de espera, item de menor satisfação dos usuários, a equipe implantou a modalidade de plantão em grupo, onde uma maior quantidade de pessoas pode ser acolhida num único atendimento. Quem aceita participar do atendimento em grupo, não fica na fila de espera do dia, sendo logo atendido e no retorno seguinte, caso haja, a pessoa tem a prioridade para o atendimento individual. Como os atendimentos do plantão não têm tempo de duração pré-determinados, o tempo de espera pode ser muito longo, a ponto de a pessoa precisar dispor de um turno inteiro para estar no serviço. A equipe sempre conversa e troca ideias sobre isso, com o objetivo de traçar estratégias que possam diminuir a espera pelos atendimentos.

No gráfico 09, referente a 2018.1, a afirmativa que teve maior satisfação foi a P09, “caso 
seja necessário, retornarei ao serviço", com 91,67\% de satisfação, isso reflete a qualidade do serviço prestado pela equipe do plantão, prezando pelo acolhimento do outro que sofre. As afirmativas P01, P03, P04, P05, P06, P08 e P10 tiveram porcentagem entre 80 a 90\%, mostrando alto grau de satisfação dos usuários nesses itens, isso reflete a qualidade do serviço de forma conjunta, clínica, equipe do plantão e infraestrutura, deixando todos os envolvidos muito contentes com o resultado que espelha o trabalho integrado da equipe. A afirmativa que teve o menor índice de satisfação continua sendo a P02, referente ao tempo de espera para ser atendido. Continuamos ofertando o plantão em grupo e além disso, implantamos a sala de espera, onde os usuários tem um acolhimento inicial, recebem orientações e são esclarecidos sobre o serviço, pois percebe-se que eles têm dificuldade em diferenciar o plantão do atendimento clínico tradicional, e como ambas as modalidades acontecem na clínica da UFC, muitos chegam ao plantão buscando psicoterapia de longo prazo, então a sala de espera tem um papel importante de psicoeducação dos usuários do serviço. A equipe continua empenhada em buscar estratégias que amenizem o impacto da espera entre os usuários, prezando pelo seu bemestar.

Gráfico 08 - pesquisa de satisfação dos usuários - 2016 a 2017

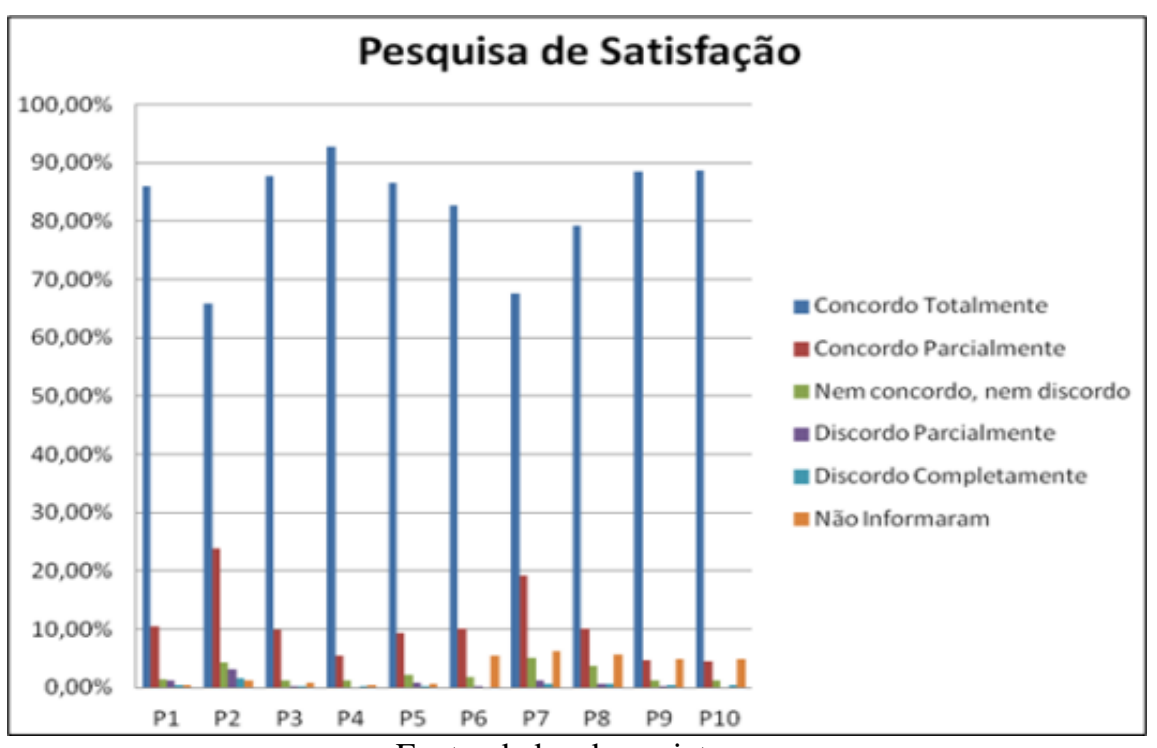

Fonte: dados do projeto. 
Gráfico 09 - pesquisa de satisfação dos usuários - 2018.1

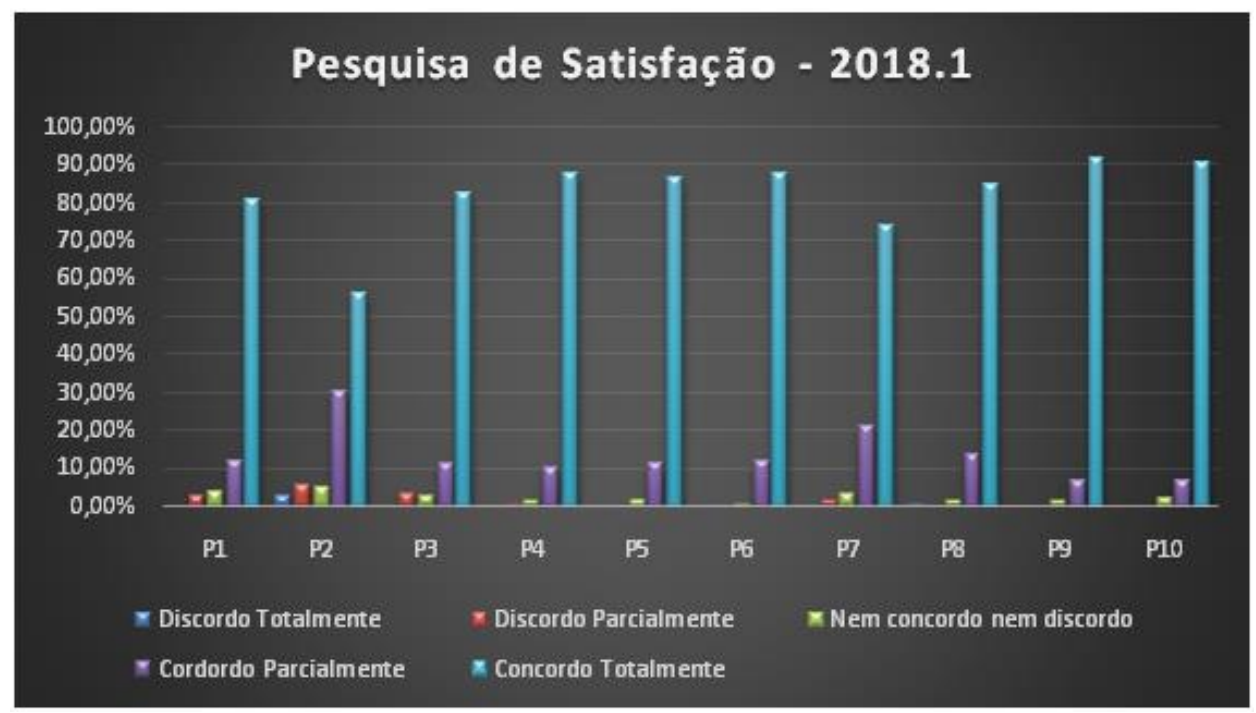

Fonte: dados do projeto

\section{CONCLUSÃO}

Considerando os dados apresentados, é possível constatar o quanto o Plantão Psicológico tem crescido ao longo desses três anos em que acontece na clínica escola de Psicologia da UFC, sendo um serviço consolidado na comunidade acadêmica e para o público em geral. Os dados da pesquisa de satisfação evidenciam a prevalência do reconhecimento da comunidade sobre a qualidade do atendimento. Os pontos de melhorias são elementos que reestruturam o serviço a cada semestre buscando sempre atender as demandas da população e as necessidades da instituição. Com este serviço, a universidade se consolida em sua relação com a sociedade e confirma sua preocupação na relação da interface ensino, pesquisa e extensão. Este serviço que transborda o atendimento clínico, nos permite esclarecer as dúvidas, orientar, acolher, diminuir a fila de espera por atendimentos na clínica escola e repensar a própria formação do futuro profissional de psicologia. É imprescindível falar sobre o papel do plantão psicológico para a formação do discente, no que tange oportunizar novas possibilidades de atuação e reflexão sobre novas modalidades de prática clínica, além de ser um contexto de intensas possibilidades de estudos e pesquisas no âmbito da graduação e pós-graduação. Tudo isso corrobora para o papel da Clínica Escola como espaço de promoção de saúde mental, para o papel do projeto como articulador e facilitador de novas práticas psicológicas e, sobretudo, para o papel da universidade como ator de mudança social e ação crítica na realidade. 


\section{REFERÊNCIAS BIBLIOGÁFICAS}

BORGES, I. L. F. BRITO, L. S.; DANTAS, J. B. Plantão Psicológico: acolhimento e escuta na clínica escola da UFC. Extensão em Ação, Fortaleza, v.2, n.14, Jul./Dez. 2017. Disponível em < hhttp://www.periodicos.ufc.br/extensaoemacao/issue/view/591ttp://

www.periodicos.ufc. br/extensaoemacao/issue/view/591 > Acesso em 21 de ago. de 2018.

DANTAS, J. B.; BENIGNO, G. G. F.; DUTRA, A. B.; BRITO, L. S.; ALVES, A.C.;

BARRETO, R. E. M. Plantão Psicológico: Ampliando possibilidades de escuta. Revista de Psicologia, v.7, n. 1, p. 223-241, 2016.

HEIDEGGER, Martin. Ser e tempo. Petrópolis: Vozes, vol. I e vol. II, 1989.

MAHFOUD, M. Desafios sempre renovados: Plantão psicológico. In: TASSINARI, M. A.; CORDEIRO, A. P. S.; DURANGE, W. T. (Org). Revisitando o plantão psicológico centrado na pessoa, p. 33-50, 2013.

REBOUÇAS, M. S. S.; DUTRA, E. Plantão psicológico: uma prática clínica da contemporaneidade. Revista da abordagem gestáltica, v. 16, n. 1, p. 19-28, 2010.

TASSINARI, M. A. Plantão psicológico como promoção de saúde. In: BACELLAR, A. A psicologia humanista na prática: reflexões sobre a abordagem centrada na pessoa. Palhoça: Editora da UNISUL, 2009.

TASSINARI, M. A.; DURANGE, W. Plantão Psicológico: O florescimento da Psicologia Pós-moderna - O Drama de uma Transmutação. Buenos Aires. Revista Enfoque Humanístico. Buenos Aires. v.1, n.1, 2012 